\title{
Advanced lung function tests in preschool children in developing country-opinion
}

\author{
Atiar Rahman* \\ Atiar Rahman FCPS MD, Associate Professor, Section of Respiratory Medicine, Department of Pediatrics, Bangabandhu Sheikh Mujib Medical University, \\ Dhaka, Bangladesh
}

\section{Introduction}

Chronic respiratory diseases represent a public health challenge in both industrialized and developing Countries because of their frequency [1]. The morbidity and mortality related to lung diseases are staggering. Hundreds of millions of people are burdened with chronic respiratory conditions; four million people die prematurely from chronic respiratory diseases each year [2] asthma causes 180,000 deaths worldwide each year, its greatest burden is the morbidity and disruption of lives [3]. Asthma afflicts 235 million people worldwide and accounts for over $30 \%$ of all pediatric hospitalizations in the United States [2], but touches the lives of many more. Its incidence is growing in both developed and developing countries. It affects all ages, races, and ethnicities, although wide variation exists between countries and within different demographic groups. The burden of asthma is greatest in urban communities, related in part to environmental exposures and lack of access to care and effective medications, especially in low-income countries [3]. In developing countries, pulmonary diseases are the leading cause of morbidity and mortality in children. Illnesses affecting the respiratory system are the most common reason for parents to seek medical care for their children in the community. Among the whole population, about $45 \%$ are children and respiratory conditions represent $45-50 \%$ of childhood illnesses. It is estimated that in Bangladesh more than 10 million people are suffering from cough and shortness of breath $[1,3]$. There is inadequate availability of advanced lung function tests and some of the respiratory diseases remain under-diagnosed. Also, advanced research work cannot be performed without relevant lung function data. The demand of Pediatric Respiratory Medicine in developing country is increasing day by day and we need to develop expertise in response to the clinical and research demand in this field. The interrupter technique (Rint) and the forced oscillation technique (FOT) or other lung function tests available for this particular age group may help to fulfill this particular demand and reduce the respiratory illness among the children [4].

Measuring lung function is particularly challenging in preschool children (2-5 years old) and physiologic measurements are often put off until the child reaches the school age. Yet, having some information on lung function may be extremely important at this age for clinical and research reasons $[4,5]$.

Active participation in the collection and interpretation of lung function tests in preschool children in an ambulatory setting using the interrupter technique (Rint) and the forced oscillation technique (FOT) or lung function tests available for this particular age group. Technical aspects, including calibration, will also important for measurement of lung function test in this particular age [5].
In many of the hospital in developing country no expertise in the field of lung functions testing in preschool children. So, need for especial attention to perform advanced lung function tests for clinical/ research purposes and potentially improve the training of other pediatric pulmonologists in pulmonology department.

Assessment of lung function in preschool children is difficult. Techniques which require active patient cooperation are difficult to perform and frequently give unreliable result [5].

The interrupter technique (Rint) is one of the few lung function tests that have been developed for assessment of airway caliber in young children. With this technique, measurement of the resistance of the respiratory system can be carried out quickly; with minimal cooperation of the child [6]. The method is particularly suitable for subject who cannot undertake standard lung function tests, such as preschool children and schoolchildren who are unable to undertake spirometry. Commercial equipment for measuring Rint is now available. Undertaking the test is not complicated, even in a busy environment, and so it is possible to measure Rint outside specialist center [7].

Rint is measuring now using two commercial devices (Micro lab 4000 and Microprint, Micro Medical Ltd, Gillingham, UK). In both device flows is measured immediately before valve closure. Pressure is measured in both using a two-point linear back extrapolation method [4,7].

\section{Technique to measure Rint}

1. Measurement will be made with the child seated, breathing through a mouthpiece and bacterial filter, nose clip in situ, and cheeks supported.

2. Occlusion should be made with a valve closing less than 10 millisecond and lasting for 100 milliseconds.

3. Occlusion will be triggered by a flow sheet to coincide with Peak expiratory flow (PEF) and will be made during expiration.

4. Ten occlusions will be recorded, with the aim of retaining a minimum of five acceptable maneuvers.

5. The median of all technically acceptable occlusions will be accepted.

${ }^{\star}$ Correspondence to: Atiar Rahman, Associate Professor, Section of Respiratory Medicine, Department of Pediatrics, Bangabandhu Sheikh Mujib Medical University, Dhaka, Bangladesh, E-Mail: atiar777@yahoo.com

Received: September 14, 2018; Accepted: September 26, 2018; Published: September 28, 2018 
The forced oscillation technique (FOT) is another most suitable device requires minimal patient cooperation and is ideally suited to subject unable to perform voluntary forced expirations. The FOT has been used in research studies for several decades and more recently, its use in clinical practice has been advocated, as reviewed by Oostven and colleagues [8].

The FOT is a noninvasive technique performed during tidal breathing that is relatively easy to apply in preschool children. An external pressure wave applied, usually at the mouth and the resulting pressure -flow relationship is analyzed in terms of respiratory impedance. The latter express the impediment to flow in the respiratory system that include both fractional losses and elastic and inertial loads [9]

Respiratory impedance spectra (Zrs), yielding Rrs and Xrs as a function of frequency, were obtained using commercially available equipment (12M, Chess Medical, Belgium) based on the specification of Landseer and coworkers in accordance with European Respiratory Society guidelines. The forced oscillatory signal is a pseudorandom signal consisting of frequency components between 4 and $48 \mathrm{~Hz}$ with a measurement period of 8 seconds $[4,9]$.

\section{Technique of FOT: 1}

1. The child will be seated, breathing through a mouthpiece, and wear a nose clip with the cheeks and mouth floor firmly supported.

2. An acquisition period will cover several breathing cycles, typically lasting 8-16 seconds

3. Three to five measurement will be performed.

4. Result will be reported as the mean of the three to five measurements and a CV will be calculated from the SD to mean ratio $[4,9]$.

\section{Conclusion}

The interrupter technique (Rint) and the forced oscillation technique (FOT) or other lung function tests available for this particular age group may help to improve clinical, training and research potential for respiratory physician and reduce the respiratory illness among the children in globe.

\section{References}

1. Lopez AD (1993) Causes of death in industrial and developing countries: estimates for 1985-1990. In: Jamison DT et al., Eds.Disease control priorities in developing countries. Washington, DC, Oxford Medical Publications 3: 35-50.

2. World Health Organization (2013) Global surveillance, prevention and control of chronic respiratory diseases: a comprehensive approach. Geneva: World Health Organization; 2013.World Health Organization. Chronic respiratory disease, asthma. 2013. Geneva: World Health Organization; 2013.

3. World Health Organization. Chronic respiratory disease, asthma. 2013. Geneva: World Health Organization; 2013

4. Lombardi E (2007) Pulmonary function test in preschool children. Am J Respir Crit Care Med 175: 1304-1345.

5. Lombardi E, Sly PD ,Concutelli G (2001) Reference value of interrupter respiratory resistance in healthy preschool white children. Thorax 56: 691-695.

6. Merkus PJFM, Arets HGM, Josten T, Siero A (2002) Measurement of interrupter resistance: reference values for children 3-13 years of age. Eur Respir J 20: 907-911.

7. McKenzie SA, Chan E, Dundas I (2002) Airway resistance measured by the interrupter technique: normative data for 2-10 years old of three ethnicities. Arch Dis Child 87 248-251.

8. Hall GL, Sly PD, Fukushima T (2007) Respiratory function in healthy young children using forced oscillations. Thorax 62: 521-526.

9. Thamrin C, Gangell CL, Udomittipong K (2007) Assessment of Bronchodilator responsiveness in preschool children using forced oscillations. Thorax 62: 814-819.

Copyright: (C2018 Rahman A. This is an open-access article distributed under the terms of the Creative Commons Attribution License, which permits unrestricted use, distribution, and reproduction in any medium, provided the original author and source are credited. 